\title{
Bioaccessibility and intestinal uptake of minerals from different types of home-cooked and ready-to-eat beans
}

\author{
Miguel A. Faria ${ }^{\mathrm{a}, 1}$, Alfredo Araújo ${ }^{\mathrm{b}, 1}$, Edgar Pinto ${ }^{\mathrm{a}, *}$, César Oliveira ${ }^{\mathrm{b}}$, M. Teresa Oliva-Teles ${ }^{\mathrm{b}}$, \\ Agostinho Almeida $^{\mathrm{a}}$, Cristina Delerue-Matos ${ }^{\mathrm{b}}$, Isabel M.P.L.V.O. Ferreira ${ }^{\mathrm{a}}$ \\ a REQUIMTE/LAQV, Departamento de Ciências Químicas, Faculdade de Farmácia da Universidade do Porto, Rua Jorge de Viterbo Ferreira 228, 4050-313 Porto, Portugal \\ ${ }^{\mathrm{b}}$ REQUIMTE/LAQV, Instituto Superior de Engenharia do Instituto Politécnico do Porto, Rua Dr. António Bernardino de Almeida, 431, 4249-015 Porto, Portugal
}

\author{
Keywords: \\ Beans \\ Minerals \\ Intestinal uptake \\ Bioaccessibility \\ Caco-2 cells
}

A B S T R A C T

Limited information exists on the bioaccessibility and intestinal uptake of essential minerals from different types of beans cooked through different cooking methods. This study aimed to estimate the in vitro bioaccessibility and intestinal uptake of the essential minerals $\mathrm{K}, \mathrm{Ca}, \mathrm{Mg}, \mathrm{Fe}, \mathrm{Zn}, \mathrm{Mn}, \mathrm{Cu}$ and $\mathrm{Mo}$ from four different types of beans (kidney, black, white and cowpea) cooked under different conditions (home-cooked and industrially processed canned product). Results showed that the bioaccessibility and uptake of most essential minerals is higher in canned beans. Mn was the mineral that presented the highest bioaccessibility (43-63\%), and Mo had the lowest (3-36\%). The highest uptake was observed for $\mathrm{Mg}$ (59.9\%), while the lowest was found for Fe (10.5\%). Regarding the type of beans, white beans presented the highest bioaccessibility and uptake for all the analyzed essential minerals and thus its consumption is preferable from a nutritional point of view.

\section{Introduction}

Common beans (Phaseolus vulgaris L.) are a staple crop in many countries of the world where people rely on this product (and cereals) to obtain most of the nutrients in order to meet their own dietary requirements. They are cultivated extensively in the five continents reaching a total production of ca. 17 million tons in 2013 (Lioi \& Piergiovanni, 2013). Another important bean genus, the cowpea [Vigna unguiculata (L.) Walp], assumes high relevance in the semi-arid tropics of Asia, Africa, southern Europe, and Central and South America. Its production reached the 5.7 million tons in 2010, although in developed countries its consumption exhibited a growing trend at the rate of $5.5 \%$ per annum, in the last years (Nedumaran et al., 2015). Both common beans and cowpeas are a relatively inexpensive source of proteins (20-25\%), complex carbohydrates (50-60\%), vitamins, and essential minerals (Baptista et al., 2017; Hayat, Ahmad, Masud, Ahmed, \& Bashir, 2014). Beans consumption has been linked with protection against inflammation, heart disease, weight gain, diabetes, certain types of cancer, and nutrient deficiencies, due to their rich nutritional composition (Rebello, Greenway, \& Finley, 2014).

The release of nutrients from raw beans is usually low due to the presence of anti-nutrients such as phytic acid, oxalate, phytohaemagglutinins, trypsin/chymotrypsin inhibitors, saponins, and polyphenols. However, it increases considerably after beans processing, because saponins, trypsin/chymotrypsin inhibitors and phytohaemagglutinins are heat unstable (Patterson, Curran, \& Der, 2017). It is well established that hydration followed by cooking or autoclaving reduces/eliminates the anti-nutrients, softens the bean matrix and improves protein and starch digestibility, facilitating the absorption of nutrients (Fernandes, Nishida, \& Da Costa, 2010).

In vitro methods that simulate the food digestion are widely used to estimate mineral bioaccessibility, defined as the fraction of the total mineral that is potentially available for uptake by intestinal brush border cell membranes. These methods comprise a simulation of the gastrointestinal digestion and are usually used together with the Caco-2 cell model in order to measure the uptake/absorption of minerals. The human epithelial cell line Caco-2 is a widely accepted model to mimic the functional and morphological properties of mature human smallintestinal enterocytes.

The bioaccessibility and intestinal uptake of minerals from beans and other pulses depends not only on their total mineral content but also on the interactions between the minerals and other food components, under different processing conditions (Drago, 2017; Hambidge, 2010). Traditionally, dry beans are home-cooked after soaking in water. 
However, the time has become a precious asset in the modern lifestyle, and industrially processed beans are currently the preferred alternative by many consumers.

Studies about the impact of cooking on the bioaccessibility and uptake of essential minerals in pulses are limited, especially for beans. The bioaccessibility of $\mathrm{Ca}, \mathrm{Cu}, \mathrm{Fe}, \mathrm{S}$ and $\mathrm{Zn}$ was recently estimated in different types of beans (Oliveira, Mateó, Fioroto, Oliveira, \& Naozuka, 2018) and the intestinal uptake of $\mathrm{Ca}, \mathrm{Fe}$ and $\mathrm{Zn}$ from lentils, white beans and chickpea was estimated using Caco-2 cells (Viadel, Barberá, \& Farré, 2006). However, none of these studies have simultaneously addressed the bioaccessibility and intestinal uptake of minerals under different cooking conditions.

The present study aimed to estimate the bioaccessibility and intestinal uptake of several essential minerals $(\mathrm{K}, \mathrm{Ca}, \mathrm{Mg}, \mathrm{Fe}, \mathrm{Zn}, \mathrm{Mn}, \mathrm{Cu}$ and Mo) from different types of beans (kidney, black, white and cowpea) under different processing conditions (home-cooked and industrially processed canned ready-to-eat).

\section{Materials and methods}

\subsection{Samples}

This study was carried out with samples of kidney, black and white beans (Phaseolus vulgaris L.) as well as cowpea beans (Vigna unguiculata subsp. Unguiculata). Three different brands of each type of bean were purchased in local supermarkets as canned "ready-to-eat" and raw dry specimens. For cowpea beans, only two brands were available in the market as raw and ready-to-eat specimens. A total of 11 samples were acquired. The selected brands were the most representative of the Portuguese market. According to the information provided by the trademark companies, the raw and canned samples were from the same country of origin and supplied by the same producer.

\subsection{Cooking procedures and hardness determination}

The cooking procedure used to obtain the "home-cooked beans" was conducted on an experimental kitchen equipped with four cooking rings and using a set of equal stainless steel cookware to ensure high repeatability in samples cooking procedure. The raw beans were previously soaked for $12 \mathrm{~h}$ in deionized water. Then they were cooked in deionized water at $100{ }^{\circ} \mathrm{C}$ during different times: kidney, black and white beans for $105 \mathrm{~min}$ and cowpea beans for $60 \mathrm{~min}$. The cooking procedure was monitored by taking off sample aliquots every $15 \mathrm{~min}$ for hardness control and was stopped when the hardness of cooked samples was similar to that of the canned bean samples.

The industrial processing of "ready-to-eat beans" was carried out by the trademark companies and involved the following stages: cleaning and classification of grains, hydration, electronic classification after hydration, blanching, packaging, addition of brine, seaming of cans, thermal processing, freezing and labeling. Details concerning the times and temperatures of thermal processing and freezing were not provided, as this information was classified as confidential by the trademark companies. For this reason, texture analysis was performed on both ready-to-eat and home-cooked beans to obtain processed beans with similar texture characteristics.

Beans hardness was monitored by a Texture Analyzer (Model XT2i, Stable Micro Systems Ltd, England) equipped with a $4.8 \mathrm{~cm}$ diameter ceramic cylinder probe, allowing a $2.5 \mathrm{~mm}$ compression at a test speed of $1.0 \mathrm{~mm} / \mathrm{s}$ after the first impact, with a trigger impact of $0.049 \mathrm{~N}$. Canned bean samples were firstly analyzed as a hardness reference control to the home-cooked beans. Each analysis involved the study of 10 different beans, which were horizontally positioned and compressed, allowing the determination of the hardness as the peak force, expressed in Newton $(\mathrm{N})$.

Home-cooked and industrially processed canned beans were dried in a laboratory drying oven (Raypa, Spain) at $105^{\circ} \mathrm{C}$ until constant weight (ca. $24 \mathrm{~h})$.

\subsection{Microwave-assisted acid digestion}

All samples were homogenized before carrying out the digestion procedures and the in vitro assays. For that purpose, ca. $30 \mathrm{~g}$ of canned or cooked beans were placed in a mortar and then crushed and homogenized. The microwave digestion system MARS-X (CEM, Mathews, NC) was used for closed vessel acid digestion of all samples. For acid digestion, $500 \mathrm{mg}$ of homogenized sample were weighed into a microwave PTFE vessel and $10 \mathrm{ml}$ of nitric acid $\left(\mathrm{HNO}_{3} 65 \% \mathrm{w} / \mathrm{w}\right.$, Merck, Darmstadt, Germany) was added. The microwave digestion program was as follow: $3 \mathrm{~min}$ at $60^{\circ} \mathrm{C}, 3 \mathrm{~min}$ at $90^{\circ} \mathrm{C}, 15 \mathrm{~min}$ at $190^{\circ} \mathrm{C}$, and cooling for $15 \mathrm{~min}$. Each sample was digested in triplicate. The certified reference material (CRM) BCR 679 was used to check the accuracy of the analysis. The same conditions were used for the acid digestion of the CRM. The results obtained were in very good agreement with the certified values (Table S1).

Supplementary data associated with this article can be found, in the online version, at https://doi.org/10.1016/j.jff.2018.10.001.

\subsection{Mineral analysis}

A ContrAA 700 high-resolution continuum source flame atomic absorption spectrometer (HRCS-FAAS, Analytik Jena, Germany) was used for the analysis of $\mathrm{K}, \mathrm{Ca}$ and $\mathrm{Mg}$. An $\mathrm{ICAP}^{\mathrm{TM}} \mathrm{Q}$ ICP-MS instrument (Thermo Fischer Scientific, Bremen, Germany) was used for the analysis of $\mathrm{Fe}, \mathrm{Cu}, \mathrm{Zn}, \mathrm{Mn}$ and Mo. The following elemental isotopes ( $\mathrm{m} / \mathrm{z}$ ratios) were monitored for analytical determinations: ${ }^{55} \mathrm{Mn},{ }^{57} \mathrm{Fe},{ }^{65} \mathrm{Cu},{ }^{66} \mathrm{Zn}$, ${ }^{98} \mathrm{Mo}$. The elemental isotopes ${ }^{45} \mathrm{Sc},{ }^{89} \mathrm{Y}$ and ${ }^{115} \mathrm{In}$ were used as internal standards.

Calibration standards for HRCS-FAAS analysis were prepared from commercial $1000 \mathrm{mg} / \mathrm{L}$ single element standard solutions of $\mathrm{Ca}, \mathrm{Mg}$ and K (Panreac, Barcelona, Spain). Calibration standards for ICP-MS analysis were prepared from a $10 \mathrm{mg} / \mathrm{L}$ multi-element standard solution (PlasmaCAL SCP-33-MS, SCP Science, Baie-d'Urfé, Quebec, Canada). The internal standards solution was prepared by appropriate dilution of the AccuTrace ${ }^{\mathrm{TM}}$ (AccuStandard ${ }^{\circledR}$, New Haven, CT) ICP-MS-200.8-IS-1 $(100 \mathrm{mg} / \mathrm{L})$ solution. All solutions were prepared using ultrapure water $\left(18.2 \mathrm{M} \Omega \mathrm{cm}\right.$ at $25^{\circ} \mathrm{C}$ ) obtained with a Sartorius (Gottingen, Germany) Arium ${ }^{\circledast}$ pro water purification system.

Results were expressed in $\mathrm{mg} / 100 \mathrm{~g}$ dry weight (dw).

\subsection{In vitro digestion}

The simulated in vitro digestion (SIVD) procedure was performed according to the internationally standardized method described by Minekus et al. (2014), using composite samples of all four types of beans. The procedure consisted of three sequential steps: an initial digestion with amylase to simulate the oral phase, followed by a digestion with pepsin/ $\mathrm{HCl}$ to simulate the gastric phase and a digestion with bile salts/pancreatin to simulate intestinal digestion. Briefly, $5 \mathrm{~g}$ of composite sample slightly triturated was mixed with $3.5 \mathrm{ml}$ of simulated salivary fluid (SSF), $0.5 \mathrm{ml}$ of $\alpha$-amylase solution at $1500 \mathrm{U} / \mathrm{ml}$ in SSF, $25 \mu \mathrm{l}$ of $0.3 \mathrm{M} \mathrm{CaCl}_{2}$ and $975 \mu \mathrm{l}$ of ultrapure water. After $2 \mathrm{~min}$ of incubation, the mixture $(10 \mathrm{ml})$ was mixed with $7.5 \mathrm{ml}$ of simulated gastric fluid (SGF), $1.6 \mathrm{ml}$ of pepsin (25,000 U/ml), $5 \mu \mathrm{l}$ of $0.3 \mathrm{M} \mathrm{CaCl}_{2}$, $200 \mu \mathrm{l}$ of $1 \mathrm{M} \mathrm{HCl}$ and $695 \mu \mathrm{l}$ of ultrapure water. The gastric mixture was then incubated in a water bath at $37{ }^{\circ} \mathrm{C}$ with gentle agitation. After incubation, $20 \mathrm{ml}$ of gastric chime were mixed with $11 \mathrm{ml}$ of simulated intestinal fluid (SIF) electrolyte solution, $5 \mathrm{ml}$ of pancreatin solution ( $800 \mathrm{U} / \mathrm{ml}$ based on trypsin activity), $2.5 \mathrm{ml}$ of bile solution $(160 \mathrm{mM}$ ), $40 \mu \mathrm{l}$ of $0.3 \mathrm{M} \mathrm{CaCl}_{2}, 150 \mu \mathrm{l}$ of $1 \mathrm{M} \mathrm{NaOH}$ and $1.31 \mathrm{ml}$ of ultrapure water. All digestions were run in triplicate. A parallel assay was performed for each sample type to determine the amount of acid or base necessary to adjust the digests $\mathrm{pH}$. Five blanks were performed and all 


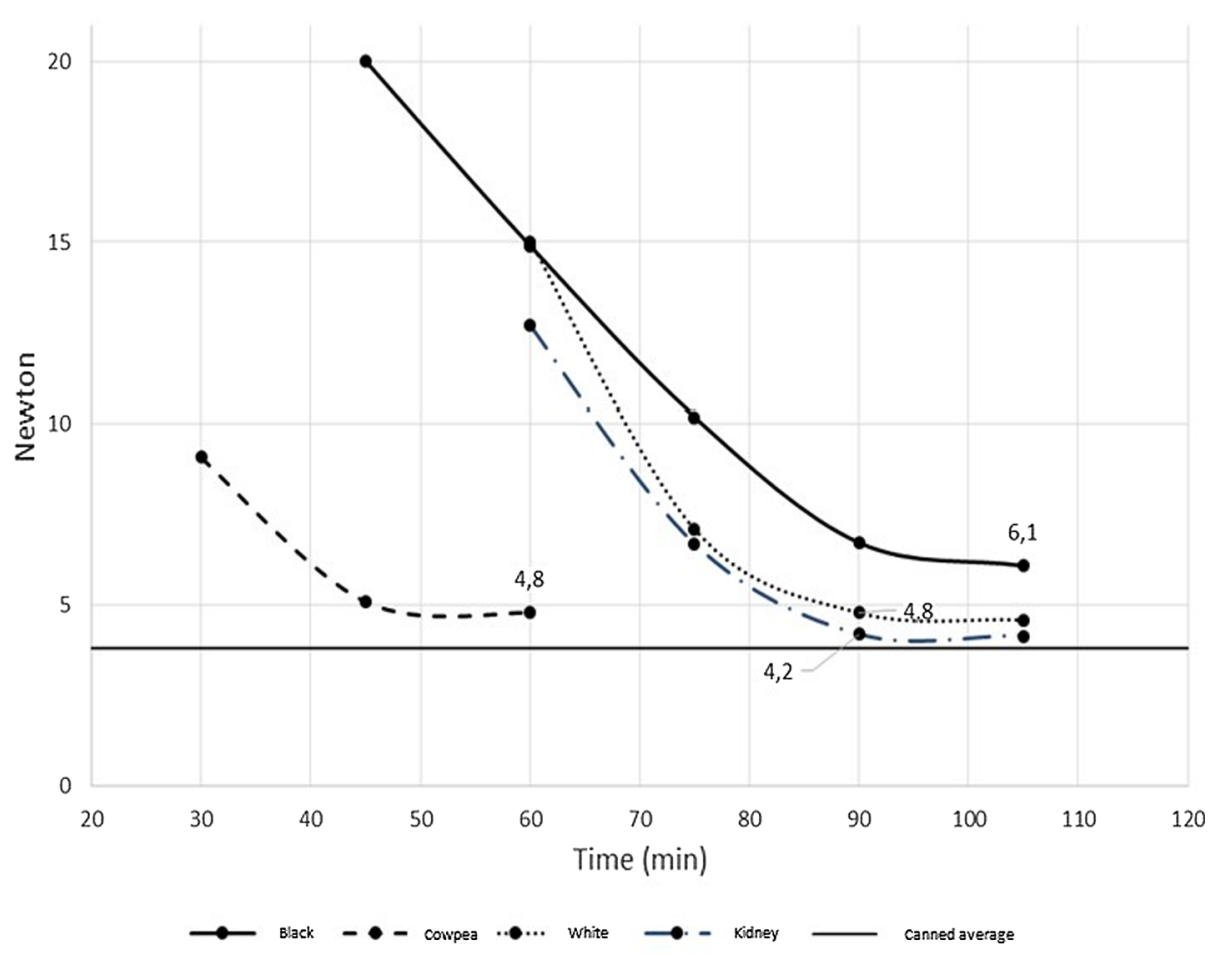

Fig. 1. Average hardness value of industrially processed canned beans and hardness values of home-cooked beans at different cooking times.

samples were blank corrected. After the simulated gastrointestinal digestion, the samples were cooled by immersion in an ice bath and centrifuged at $5000 \mathrm{~g}$ for $10 \mathrm{~min}$ at $4{ }^{\circ} \mathrm{C}$ to separate the soluble bioaccessible fraction from the residual fraction. Supernatants from the bioaccessible fraction were then filtered using $0.22 \mu \mathrm{m}$ PES membrane syringe filters and then frozen at $-20^{\circ} \mathrm{C}$ until analysis. Samples were taken to mineral analysis at two different digestion points corresponding to the end of the gastric phase $(2 \mathrm{~h})$ and intestinal phase $(4 \mathrm{~h})$. Bioaccessibility was calculated as follows:

Bioaccessibility $(\%)=\frac{\text { mineral content }(\mathrm{mg} / 100 \mathrm{~g}) \text { in the intestinal fraction }}{\text { total mineral content }(\mathrm{mg} / 100 \mathrm{~g})} \times 100$

\subsection{Cell culture}

Caco- 2 cells were routinely maintained in DMEM supplemented with $10 \%$ fetal bovine serum, $1 \%$ non-essential amino acids solution, $100 \mathrm{U} / \mathrm{ml}$ penicillin, $100 \mu \mathrm{g} / \mathrm{ml}$ streptomycin and $1 \%$ GlutaMAX $^{\mathrm{TM}}$ solution. Cells were incubated at $37{ }^{\circ} \mathrm{C}$ under $5 \% \mathrm{CO}_{2}$ atmosphere. Medium was changed every two days and cells passed at $60 \%$ confluence. For permeability assays, cells were used between passages 35 and 46. Contamination with mycoplasma was assessed by PCR every month using the protocol described by van Kuppeveld et al. (1992).

\subsection{Transport assays to estimate intestinal uptake}

Caco- 2 cells were seeded in a density of $1 \times 10^{5}$ cells $/ \mathrm{cm}^{2}$ in $24 \mathrm{~mm}$ 6 well Transwell ${ }^{\circledR}$ plates with a pore size of $0.4 \mu \mathrm{m}$ and a growth area of $4.67 \mathrm{~cm}^{2}$ (Corning Inc., Corning, NY). The medium was changed every two days and the transport experiments were conducted 21 days post seeding. After the differentiation period, the transepithelial electric resistance (TEER) was determined using the Millicell ERS-2 Voltohmmeter (Merck Millipore, Darmstadt, Germany). Only monolayers with a TEER value $>1000 \Omega \mathrm{cm}^{2}$ were considered to the transport assay. During the transport experiments the Caco-2 cells were exposed in the apical (AP) compartment to $2.5 \mathrm{ml}$ of the mixture composed by the final digests, filtered through $0.22 \mu \mathrm{m}$ Nylon syringe filters and diluted $1+2$ in transport medium $(130 \mathrm{mM} \mathrm{NaCl}, 10 \mathrm{mM}$ $\mathrm{KCl}, 1 \mathrm{mM} \mathrm{MgSO}$, $50 \mathrm{mM}$ HEPES, and $5 \mathrm{mM}$ glucose, at $\mathrm{pH}$ 7.2). The AP compartment was filled with $1.5 \mathrm{ml}$ of transport medium. Transport was measured after $2 \mathrm{~h}$ of incubation at $37^{\circ} \mathrm{C}$ with gentle agitation. Samples were then collected from both AP and basolateral (BL) compartments and stored at $-20{ }^{\circ} \mathrm{C}$ until analysis. TEER values were also determined at the end of the experiment after monolayer washing twice with transport medium. The cells were lysed and harvested through the addition of concentrated $\mathrm{HNO}_{3}(65 \% \mathrm{w} / \mathrm{w})$. All transport assays were performed in triplicate.

Retention, transport and uptake were calculated as follows:

$$
\begin{aligned}
& \text { Retention }(\%)=\frac{\text { mineral }(\mu \mathrm{g}) \text { in lysed cells-mineral }(\mu \mathrm{g}) \text { in apical compartment }}{\text { mineral added }(\mu \mathrm{g})} \\
& \text { Transport }(\%) \\
& =\frac{\text { mineral }(\mu \mathrm{g}) \text { in basolateral compartment-mineral }(\mu \mathrm{g}) \text { in transport buffer }}{\text { mineral added }(\mu \mathrm{g})}
\end{aligned}
$$

Uptake percentages were achieved by the sum of Transport and Retention percentage values.

\subsection{Statistical data analysis}

Statistical analysis was performed using IBM (New York, NY) SPSS Statistics 25 software. A Shapiro-Wilk's test was performed to assess the normality of data. The assumption of homogeneity of variance was tested using Levene's test. The differences in the minerals content among the different types of beans (kidney, black, white and cowpea) were evaluated through the non-parametric Welch ANOVA followed by Games-Howell post hoc test. Student's $t$-tests were used to evaluate differences between types of cooking (cooked vs canned). Statistical significance was considered for $\mathrm{p}$ value below 0.05 .

\section{Results and discussion}

\subsection{Cooking time selection}

Fig. 1 presents hardness change in the different types of bean during 
the cooking procedure after soaking. The average hardness determined for canned beans was around $4.2 \mathrm{~N}$. The cooking time required to obtain a similar hardness on home-cooked beans depended on the type of bean. Cowpea beans achieved a hardness around $4.8 \mathrm{~N}$ after $60 \mathrm{~min}$ of cooking, while kidney, black and white beans required $105 \mathrm{~min}$. Kidney, white and cowpea beans presented a similar hardness compared to canned beans after the cooking times previously mentioned. Only black beans presented a slightly harder texture $(6.1 \mathrm{~N})$ even after 105 min of cooking, yet, a higher cooking time was not applied because it destroyed the beans physical structure (data not shown). The obtained values are in good agreement with those published by Chigwedere et al. (2018), who found an average hardness of $5 \mathrm{~N}$ for cooked bean and values ranging from 9.1 to $20 \mathrm{~N}$ for soaked uncooked beans. After the selected cooking periods, beans presented a soft texture, being easily crushed by fingers compression, and so, ready for eating. Thus, all samples were boiled accordingly to the optimized cooking times.

\subsection{Total mineral content}

The analysis of the minerals content of cooked and canned beans showed $\mathrm{K}$ as the most abundant mineral and Mo as the less abundant (Table 1). Significant differences were observed between the different types of bean (kidney, black, white and cowpea) and between cooking procedures (home-cooked and canned).

Regarding cooked beans, black and white beans presented a significantly higher $\mathrm{K}$ content, while kidney beans presented a significantly lower $\mathrm{Mg}$ content. Cowpea beans showed a significantly higher $\mathrm{Mg}$ content and lower $\mathrm{Ca}$ content. No significant differences were observed between the Fe content of the different types of beans. Cowpea beans presented a significantly higher $\mathrm{Zn}$ and $\mathrm{Cu}$ content and black and white beans showed a significantly higher $\mathrm{Mn}$ content. Kidney and white beans showed a significantly higher Mo content.

With respect to canned beans, black beans showed a significantly lower $\mathrm{K}$ and $\mathrm{Mg}$ content and cowpea beans presented a significantly lower $\mathrm{Ca}$ and Fe content. White beans presented a significantly high $\mathrm{Mg}$ content, while kidney and cowpea beans showed a significantly higher Zn content. Kidney and white beans presented a significantly higher Mo content. No significant differences were observed between the $\mathrm{Mn}$ and $\mathrm{Cu}$ content of the different types of canned beans.

In general, canned beans presented a significantly lower content of all essential elements compared to cooked beans, the exception being $\mathrm{Ca}$ in kidney and white beans. The highest difference between contents in cooked and canned beans was observed for Mo (canned beans had on average, $48 \%$ less Mo). However, it must be emphasized that the differences in the mineral content between cooked and canned were highly dependent on the type of bean. For example, the $\mathrm{Mg}$ content decreased by only $1 \%$ and $6 \%$ in kidney and white beans, respectively, but it decreased by $35 \%$ and $31 \%$ in black and cowpea beans, respectively. This reduction seems to be related to the higher leaching of minerals during the industrial processing compared to the home cooking process. Overall, these results are in agreement with literature data. Pedrosa et al. (2015) study the effects of industrial canning on the nutritional profile of two common beans and concluded that the content of $\mathrm{Ca}, \mathrm{Mg}, \mathrm{Fe}$ and $\mathrm{Zn}$ also decreased after industrial canning.

For data comparison, the minerals content obtained in the present study for kidney, black, white and cowpea beans was compared with the values described in national food databases from several countries, i.e., Canada, Czech Republic, Finland, France, Italy, Norway, Portugal, Spain, Switzerland, UK and USA (BDA, 2015; BEDCA, 2016; CFCD, 2016; CIQUAL, 2017; CNF, 2018; CoFID, 2015; Fineli, 2017; FSVO, 2017; INSA, 2018; NFCT, 2017; USDA, 2018). An average value for each mineral was calculated based on the information provided by each national food database. The minerals content obtained in the present study are in good agreement with the calculated average values for all minerals, except for $\mathrm{Ca}$, for which the values obtained in the present study were always below, regardless the type of bean or type of cooking procedure (home-cooked or canned ready-to-eat).

\subsection{Mineral bioaccessibility}

Fig. 2 present the bioaccessible fraction (\%) of the analyzed minerals after the gastric and intestinal digestions. Overall, an increase was observed in the bioaccessible fraction with the successive digestion procedures (from gastric to the intestinal digestion) for all the minerals. For $\mathrm{K}, \mathrm{Ca}, \mathrm{Zn}, \mathrm{Mn}$ and $\mathrm{Mo}$, the bioaccessible fraction was up to 2-fold higher for the intestinal digestion compared to the gastric digestion, while for $\mathrm{Mg}$ and $\mathrm{Cu}$, the bioaccessible fraction after intestinal digestion was ranged from 2 to 4 times the bioaccessible fraction after the gastric digestion. For $\mathrm{Fe}$, the bioaccessible fraction after the intestinal digestion was from 1.2 to 8 times higher than the bioaccessible fraction after the gastric digestion. Regarding the gastric digestion, Mn was the mineral that presented the highest bioaccessibility and Fe the lowest. For the intestinal digestion, $\mathrm{Mn}$ was also the mineral that showed the highest bioaccessibility and Mo the lowest. Despite this, significant differences were observed among the different cooking procedures and types of bean.

Regarding the different cooking procedures, the bioaccessibility of $\mathrm{Zn}$ was significantly higher in canned beans compared to home-cooked beans, regardless the type of bean (kidney, black, white or cowpea). In contrast, the bioaccessibility of $\mathrm{Cu}$ was significantly higher in all types of home-cooked beans. The bioaccessibility of $\mathrm{K}, \mathrm{Fe}$ and $\mathrm{Mn}$ was significantly higher in three types of canned beans compared to homecooked beans. The bioaccessibility of Mo was also significantly higher in white and cowpea canned beans. For $\mathrm{Ca}$ and $\mathrm{Mg}$, the bioaccessibility was highly dependent on the bean type. For example, Mg bioaccessibility was significantly higher in home-cooked white beans $(55.3 \%$ vs. $37.7 \%$ in canned white beans), while it was significantly lower in home-

Table 1

Total mineral content of beans (mean $\pm \mathrm{SD}, \mathrm{mg} / 100 \mathrm{~g}, \mathrm{n}=3$ ).

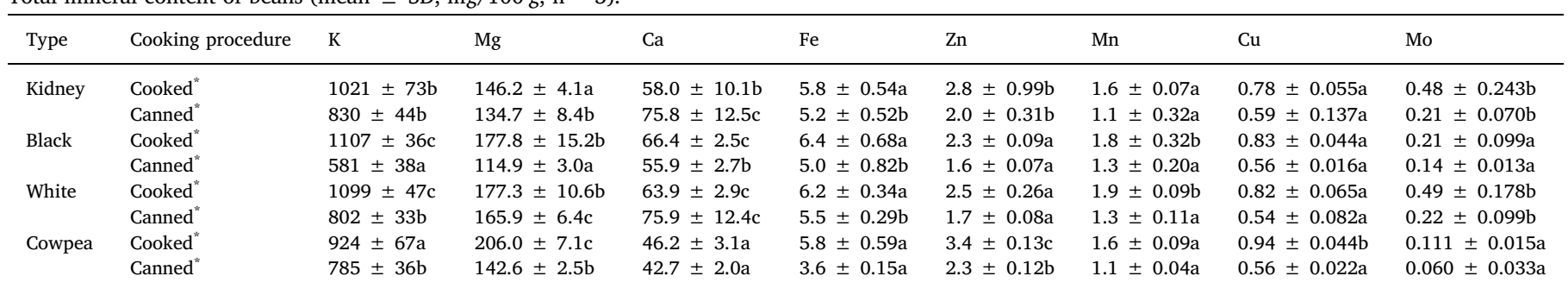

In a column, different letters (a, b, c and d) indicate significant differences between the different types of bean (kidney, black, white and cowpea) for a particular cooking procedure.

In a column and for each type of bean, the symbol * indicates significant differences between cooking procedures (home-cooked vs. industrially processed canned product). 

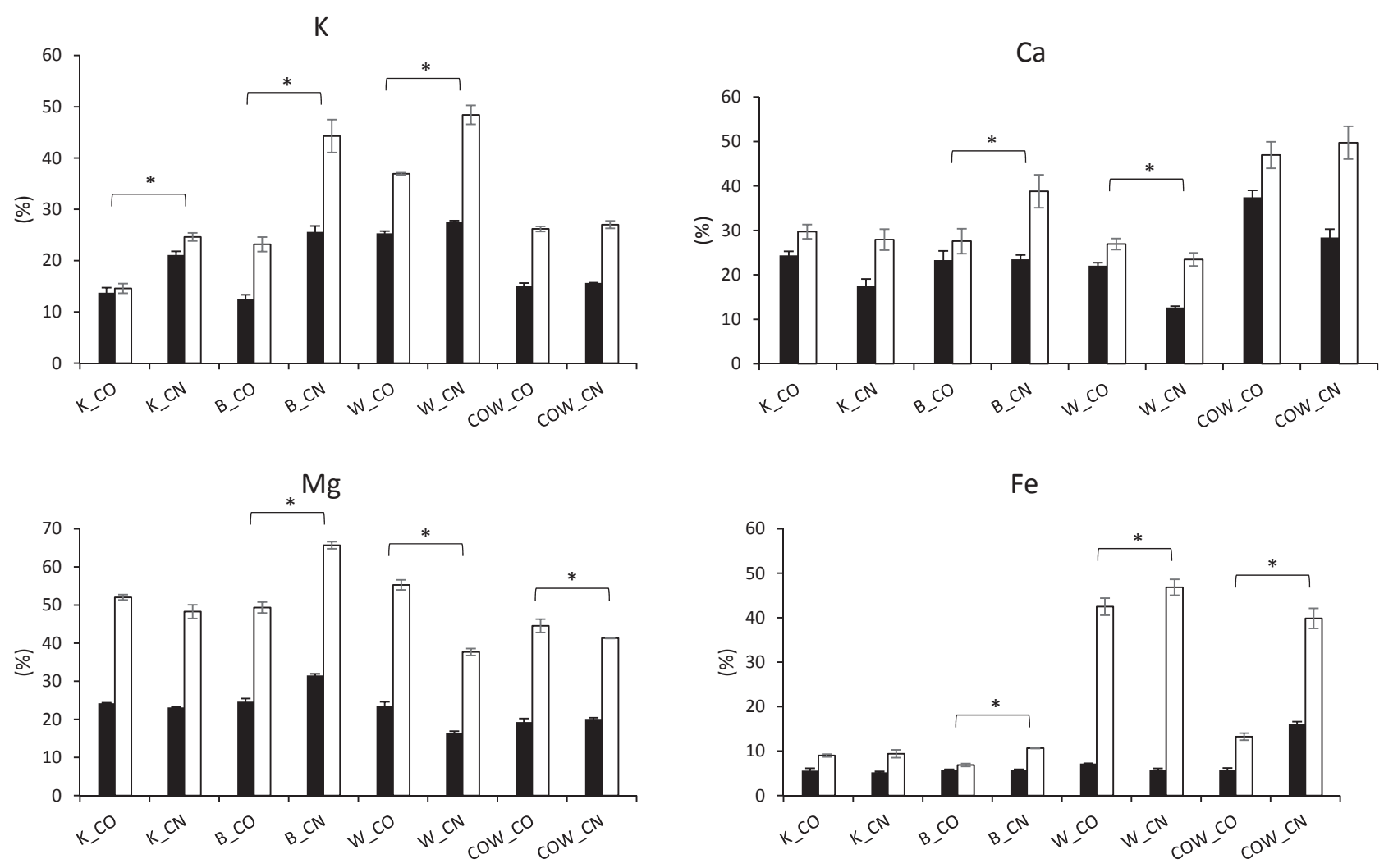

$\mathrm{Fe}$
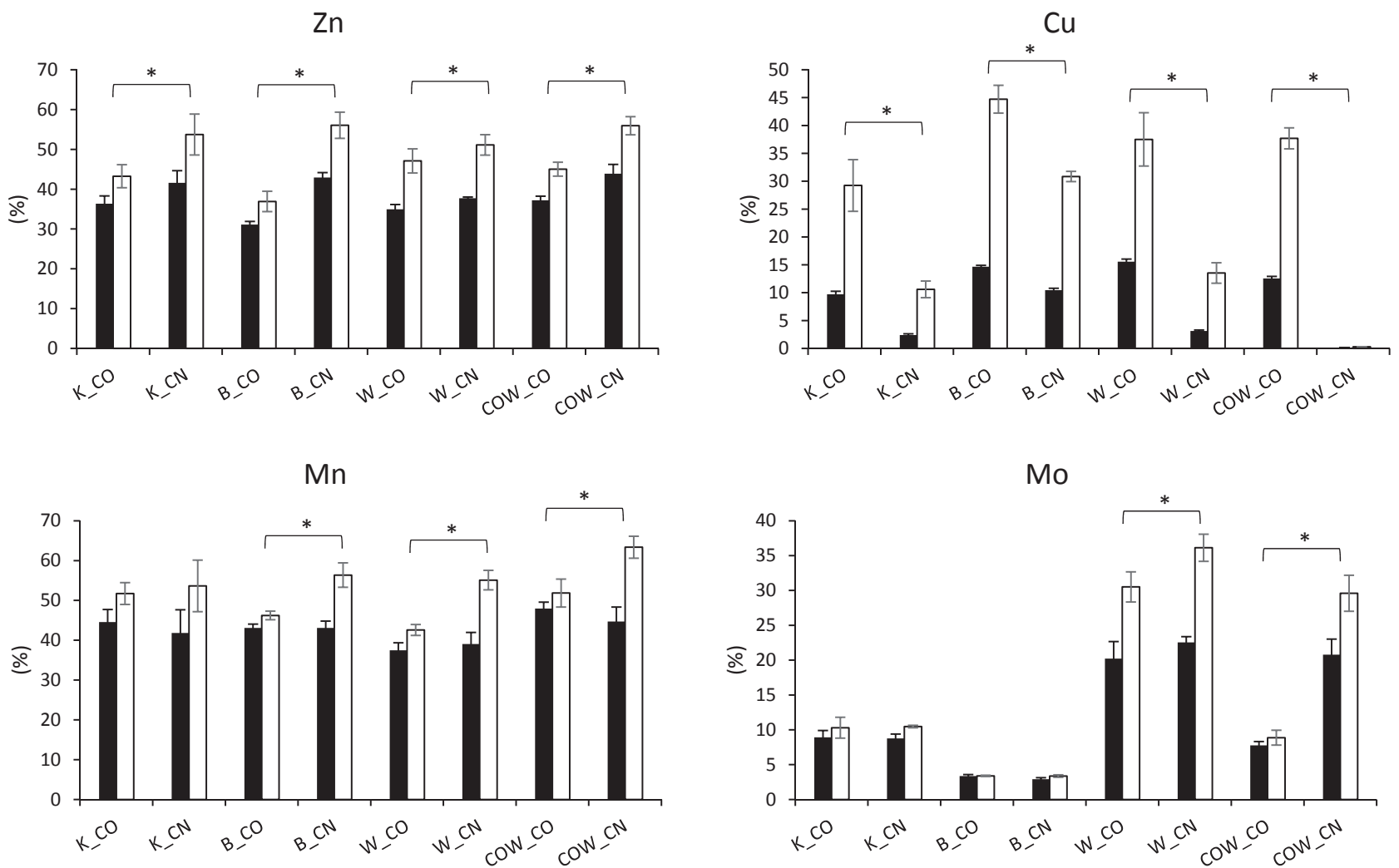

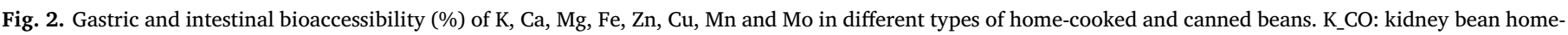

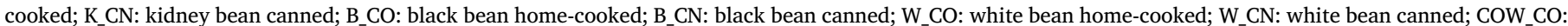

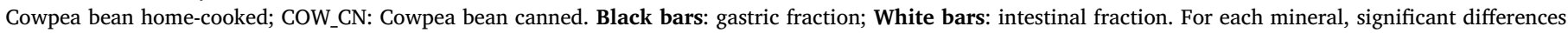
between cooking procedures (home-cooking vs. industrially canned) are marked with the symbol *. 
cooked black beans (49.3\% vs. $65.7 \%$ in canned black beans) (Fig. 2).

Regarding the type of bean, several differences were observed for all minerals. For cooked beans, kidney beans presented a significantly lower K bioaccessibility (14.6\%), while white beans presented a significantly higher $\mathrm{K}, \mathrm{Fe}$ and Mo bioaccessibility (36.9\%, 42.5\% and $30.5 \%$, respectively). Cooked cowpea beans showed a significantly higher Ca bioaccessibility (47.0\%) and a significantly lower $\mathrm{Mg}$ bioaccessibility (44.5\%). Cooked black beans presented a significantly lower Mo bioaccessibility (3.4\%). For canned beans, white beans presented a significantly lower $\mathrm{Mg}$ bioaccessibility (37.7\%) and a significantly higher Fe and Mo bioaccessibility (46.8\% and $36.1 \%$, respectively). Canned black beans showed a significantly lower Mo bioaccessibility (3.4\%) and a significantly higher $\mathrm{Mg}$ and $\mathrm{Cu}$ bioaccessibility $(65.7 \%$ and $30.8 \%$, respectively). Canned cowpea beans presented a significantly lower $\mathrm{Cu}$ bioaccessibility (0\%) and a significantly higher Ca bioaccessibility (49.7\%). In short, it can be said that the bioaccessibility of Ca showed to be higher in cowpea beans and the bioaccessibility of Fe and Mo showed to be higher in white beans, regardless of the type of cooking.

Data comparison is difficult because few studies have been published on the bioaccessibility of minerals in beans after cooking. In addition, most of those studies only reported data on the bioaccessibility of minerals in raw/uncooked beans. In one study, Oliveira, et al. (2018) found a bioaccessible fraction of $30 \%$ and $24 \%$ for Ca in cooked kidney and black beans, respectively, values similar to those obtained in this study $(29.7 \%$ and $27.6 \%)$. For $\mathrm{Cu}$, they found a bioaccessible fractions of $41 \%, 43 \%$ and $21 \%$ in kidney, black and cowpea beans, respectively, while in the present study it was found quite different bioaccessible fractions (29\%, $45 \%$ and $38 \%$ ). For $\mathrm{Zn}$, the authors found bioaccessible fractions ranging from 0 to $131 \%$, which are very different from the ones found in the present study (43\%, 37\% and $45 \%$ for kidney, black and cowpea beans, respectively). Suliburska and Krejpcio (2014) also studied the bioaccessibility of $\mathrm{Fe}, \mathrm{Zn}, \mathrm{Ca}$ and $\mathrm{Mg}$ in beans and found similar values to ours for Fe ( $9.4 \%$ vs. $9.2 \%)$, Zn (52.0\% vs. $48.6 \%$ ) and $\mathrm{Ca}(27.5 \%$ vs. $28.8 \%)$. However, a quite different value was observed for $\mathrm{Mg}$ ( $12.4 \%$ vs. $50.2 \%$ in our study). No data are available in the literature regarding the bioaccessibility of minerals in ready-toeat canned beans, thus, no comparisons can be made. Likewise, no data are available about the bioaccessibility of the studied minerals in the gastric phase hence no data comparison was can be made.

Several factors are known to affect the bioaccessibility of minerals in beans and other legumes. Among these, levels of phytic acid and polyphenols are known to play a key role in determining the fraction of minerals that may become bioaccessible. Hemalatha, Platel, and Srinivasan (2007) studied the bioaccessibility of $\mathrm{Zn}$ and Fe in cereals and pulses and found a significant negative correlation between the phytic acid content and Zn bioaccessibility in pulses and between the phytic acid content and Fe bioaccessibility in cereals. More recently, Liang, Han, Nout, and Hamer (2010) used an in vitro solubility assay to compare rice-based foods from China. The authors found that a high content of phytic acid in the brown rice resulted in the lower Ca solubility among all tested rice foods. The negative influence of phytic acid on the bioaccessibility of minerals is well known and, therefore, several technological strategies, such as milling, soaking, fermentation, germination, gave been proposed to reduce the amount of phytic acid in food (Etcheverry, Grusak, \& Fleige, 2012; Gupta, Gangoliya, \& Singh, 2015). Polyphenols can also influence the bioaccessibility of minerals in specific foods. Vitali, Vedrina Dragojević, and Šebečić (2008) evaluated the influence of polyphenols on the bioaccessibility of $\mathrm{Ca}, \mathrm{Mg}, \mathrm{Mn}$ and $\mathrm{Cu}$ from whole grain tea-biscuits. The authors found that the bioaccessibility of $\mathrm{Ca}$ and $\mathrm{Mg}$ was negatively correlated with the content of polyphenols and phytates, whereas the bioaccessibility of $\mathrm{Mn}$ is mainly negatively correlated with phytic acid content.

\subsection{Cell retention, transport and uptake}

The uptake values for $\mathrm{Ca}, \mathrm{Mg}, \mathrm{Fe}$ and $\mathrm{Zn}$ in both cooked and canned beans are presented in Table 2. Results are expressed in percentage of mineral retention in the Caco- 2 cells, transport across Caco- 2 cells and uptake (calculated as the sum of cell retention and transport). The values for $\mathrm{K}, \mathrm{Mn}, \mathrm{Cu}$ and Mo were always below the limit of detection (LOD) (Table S2) and thus were not considered here. For the remaining four elements ( $\mathrm{Ca}, \mathrm{Mg}, \mathrm{Fe}$ and $\mathrm{Zn}$ ), the transport percentage was always well above the cell retention percentage, regardless of the type of bean or type of cooking. The highest uptake was observed for Mg (59.9\%), followed by $\mathrm{Zn}(29.0 \%)$, Ca (24.9\%) and finally by Fe (10.5\%). These results are in reasonable agreement with the literature data. Cámara, Barberá, Amaro, and Farré (2007) studied the intestinal uptake of Ca, $\mathrm{Fe}, \mathrm{Zn}$ and $\mathrm{Cu}$ in several foods and found, for lentils, that the highest uptake was observed for $\mathrm{Ca}(45.9 \%)$ and the lowest for $\mathrm{Fe}(7.98 \%)$. In the same study, $\mathrm{Zn}$ uptake was of $31.3 \%$ in lentils. Similar results were also observed in a study by Viadel et al. (2006), where the authors found that the intestinal uptake of $\mathrm{Ca}$ and $\mathrm{Zn}$ was of 6.54 and $2.08 \%$, respectively. In the same study, no Fe was detected after the transport assay with Caco- 2 cells. The same authors evaluated the intestinal uptake of $\mathrm{Ca}, \mathrm{Zn}$ and $\mathrm{Fe}$ in white beans and found a different trend, i.e., the highest uptake was observed for $\mathrm{Fe}(33.78 \%)$, which was followed by $\mathrm{Ca}(18.77 \%)$ and $\mathrm{Zn}(17.2 \%)$. Data on the intestinal uptake of minerals in cooked beans is very scarce and only the abovementioned two works present results for a specific group of minerals (Ca, Fe, $\mathrm{Zn}$ and $\mathrm{Cu})$. Our study presents data on $\mathrm{Mg}$ uptake but no data is available in the literature for comparison. To the best of our knowledge, very little research has been done on $\mathrm{Mg}$ uptake although its deficiency is a worldwide concern, highlighting the need of further works on the subject.

Regarding the cooking procedures, canned beans showed a higher uptake of all the four minerals ( $\mathrm{Ca}, \mathrm{Mg}$, Fe and $\mathrm{Zn}$ ) compared to cooked beans. The uptake of $\mathrm{Ca}$ in canned beans was 1.4 to 1.7 times higher than in cooked beans. A similar result was observed for $\mathrm{Mg}$ and $\mathrm{Fe}$ whose uptake was, respectively, 1.1 to 1.4 times higher and 1.4 to 1.9 times higher in canned beans. For Zn, these differences were even more noticeable since its uptake was 1.7 to 2.8 times higher in canned beans. The comparison of these results with literature data is not possible due to the lack of information on this particular subject. The only study that compared the uptake of minerals in cooked and canned beans was the study of Viadel et al. (2006). These authors observed an increase of Ca, $\mathrm{Fe}$ and $\mathrm{Zn}$ uptake in ready-to-eat lentils $(7.58,9.47$ and $8.13 \%$, respectively) compared to traditional cooked ones $(6.54,<$ LOD and $2.08 \%$, for $\mathrm{Ca}, \mathrm{Fe}$ and $\mathrm{Zn}$, respectively). They state that this occurs because ready-to-eat lentils are soaked in EDTA during their preparation, which protects minerals, especially Fe, from reacting with phytic acid, which would reduce their ability to be transported across the intestinal barrier. Thus, by reacting with EDTA, the soluble Ca-EDTA, FeEDTA or Zn-EDTA complexes can be absorbed in their actual form or the minerals can be released from these complexes to be absorbed later in the intestinal lumen. The same authors also stated that two others factors may have contributed to increase $\mathrm{Ca}$, Fe and $\mathrm{Zn}$ uptake in readyto-eat lentils: (1) the addition of ascorbic or citric acids, commonly added to canned products, and (2) the use of high-pressure cooking. These two factors may have played a key role in increasing the uptake of $\mathrm{Ca}, \mathrm{Fe}$ and $\mathrm{Zn}$ in ready-to-eat lentils. A great body of literature exists supporting that the addition of EDTA and organic acids, such as citric or ascorbic acid, can increase the bioaccessibility and uptake of minerals (Etcheverry et al., 2012). In a study conducted by Walter, Pizarro, and Olivares (2003), the authors tested the efficacy of using disodium EDTA $\left(\mathrm{Na}_{2}\right.$ EDTA) in increasing the bioaccessibility of $\mathrm{Fe}$ in tortillas. Different Fe salts, both in the presence and absence of $\mathrm{Na}_{2}$ EDTA, were added to the tortillas and the results showed that the bioaccessibility of Fe was higher when Fe-Na ${ }_{2}$ EDTA was used. Kloots, Op den Kamp, and Abrahamse (2004), who evaluated the effect of adding different sources 
Table 2

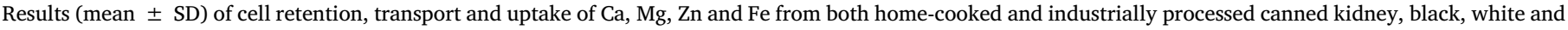
cowpea beans.

\begin{tabular}{|c|c|c|c|c|}
\hline & \multicolumn{4}{|l|}{$\mathrm{Ca}$} \\
\hline & $\begin{array}{l}\text { Mass added } \\
(\mu \mathrm{g})\end{array}$ & $\begin{array}{l}\text { Cell retention } \\
(\%)\end{array}$ & Transport (\%) & Uptake $^{*}(\%)$ \\
\hline Home-cooked kidney & 21.9 & $3.2 \pm 0.6$ & $17.5 \pm 0.5$ & $20.7 \pm 0.6$ \\
\hline Canned kidney & 25.5 & $8.0 \pm 1.4$ & $20.4 \pm 3.9$ & $28.3 \pm 2.7$ \\
\hline Home-cooked black & 21.3 & $2.7 \pm 1.3$ & $15.8 \pm 1.7$ & $18.5 \pm 1.5$ \\
\hline Canned black & 23.3 & $7.7 \pm 4.8$ & $23.6 \pm 1.3$ & $31.2 \pm 3.1$ \\
\hline Home-cooked white & 20.7 & $9.4 \pm 2.6$ & $14.3 \pm 3.8$ & $23.7 \pm 3.2$ \\
\hline Canned white & 24.1 & $8.0 \pm 0.3$ & $24.9 \pm 0.8$ & $32.9 \pm 0.6$ \\
\hline Home-cooked cowpea & 21.9 & $10.0 \pm 2.4$ & $7.1 \pm 0.9$ & $17.1 \pm 1.7$ \\
\hline Canned cowpea & 23.1 & $9.3 \pm 3.8$ & $18.7 \pm 3.1$ & $28.0 \pm 3.4$ \\
\hline \multirow[t]{3}{*}{ Average } & - & $7.1 \pm 2.7$ & $17.8 \pm 5.6$ & $24.9 \pm 6.1$ \\
\hline & \multicolumn{4}{|l|}{$\mathrm{Mg}$} \\
\hline & $\begin{array}{l}\text { Mass added } \\
(\mu \mathrm{g})\end{array}$ & $\begin{array}{l}\text { Cell retention } \\
(\%)\end{array}$ & Transport (\%) & Uptake (\%) \\
\hline Home-cooked kidney & 74.3 & $0.8 \pm 0.1$ & $54.9 \pm 0.7$ & $55.7 \pm 0.4$ \\
\hline Canned kidney & 66.5 & $0.9 \pm 0.8$ & $61.2 \pm 0.2$ & $62.1 \pm 0.5$ \\
\hline Home-cooked black & 80.3 & $3.2 \pm 0.3$ & $48.9 \pm 1.9$ & $52.2 \pm 1.1$ \\
\hline Canned black & 73.1 & $5.6 \pm 1.5$ & $54.9 \pm 0.2$ & $60.4 \pm 0.8$ \\
\hline Home-cooked white & 88.1 & $6.2 \pm 1.3$ & $46.6 \pm 0.4$ & $52.7 \pm 0.9$ \\
\hline Canned white & 59.7 & $2.6 \pm 0.9$ & $68.4 \pm 3.2$ & $71.1 \pm 2.1$ \\
\hline Home-cooked cowpea & 86.8 & $4.4 \pm 0.3$ & $47.8 \pm 1.2$ & $52.2 \pm 0.7$ \\
\hline Canned cowpea & 57.0 & $1.3 \pm 0.4$ & $71.2 \pm 0.9$ & $72.5 \pm 0.6$ \\
\hline \multirow[t]{3}{*}{ Average } & - & $3.1 \pm 2.1$ & $56.7 \pm 9.4$ & $59.9 \pm 8.2$ \\
\hline & \multicolumn{4}{|l|}{$\mathrm{Fe}$} \\
\hline & $\begin{array}{l}\text { Mass added } \\
(\mu \mathrm{g})\end{array}$ & $\begin{array}{l}\text { Cell retention } \\
(\%)\end{array}$ & Transport (\%) & Uptake (\%) \\
\hline Home-cooked kidney & 0.45 & $2.1 \pm 1.5$ & $6.2 \pm 0.9$ & $8.3 \pm 1.2$ \\
\hline Canned kidney & 0.49 & $1.0 \pm 0.3$ & $9.6 \pm 1.6$ & $10.6 \pm 0.9$ \\
\hline Home-cooked black & 0.48 & $2.5 \pm 0.7$ & $8.5 \pm 0.8$ & $11.0 \pm 0.8$ \\
\hline Canned black & 0.53 & $1.0 \pm 0.1$ & $10.7 \pm 1.3$ & $11.7 \pm 0.4$ \\
\hline Home-cooked white & 2.40 & $1.1 \pm 0.4$ & $7.2 \pm 1.1$ & $8.3 \pm 0.7$ \\
\hline Canned white & 2.37 & $1.1 \pm 0.2$ & $11.9 \pm 0.6$ & $13.0 \pm 0.4$ \\
\hline Home-cooked cowpea & 0.69 & $1.1 \pm 0.6$ & $6.0 \pm 0.1$ & $7.1 \pm 0.3$ \\
\hline Canned cowpea & 1.36 & $3.8 \pm 1.3$ & $9.9 \pm 0.4$ & $13.7 \pm 0.7$ \\
\hline \multirow[t]{3}{*}{ Average } & - & $1.7 \pm 1.0$ & $8.8 \pm 2.1$ & $10.5 \pm 2.4$ \\
\hline & \multicolumn{4}{|l|}{$\mathrm{Zn}$} \\
\hline & $\begin{array}{l}\text { Mass added } \\
(\mu \mathrm{g})\end{array}$ & $\begin{array}{l}\text { Cell retention } \\
(\%)\end{array}$ & Transport (\%) & Uptake (\%) \\
\hline Home-cooked kidney & 1.19 & n.d. & $11.5 \pm 6.5$ & $11.5 \pm 6.5$ \\
\hline Canned kidney & 0.90 & $2.5 \pm 1.8$ & $29.2 \pm 1.8$ & $31.7 \pm 1.8$ \\
\hline Home-cooked black & 0.90 & $2.2 \pm 0.7$ & $14.7 \pm 1.3$ & $16.8 \pm 1.0$ \\
\hline Canned black & 0.88 & $2.9 \pm 2.3$ & $40.3 \pm 1.7$ & $43.2 \pm 2.0$ \\
\hline Home-cooked white & 1.07 & $1.6 \pm 0.4$ & $24.6 \pm 6.5$ & $26.2 \pm 3.4$ \\
\hline Canned white & 0.88 & n.d. & $58.1 \pm 5.3$ & $58.8 \pm 2.8$ \\
\hline Home-cooked cowpea & 1.47 & $4.2 \pm 2.6$ & $12.0 \pm 3.9$ & $16.2 \pm 3.3$ \\
\hline Canned cowpea & 1.23 & $7.4 \pm 2.6$ & $19.9 \pm 4.5$ & $27.3 \pm 3.6$ \\
\hline Average & - & $2.7 \pm 2.3$ & $26.3 \pm 16.1$ & $29.0 \pm 15.7$ \\
\hline
\end{tabular}

n.d., not detected.

* Uptake $=$ cell retention + transport.

of Fe to whole-grain wheat flour, found that using Fe- $\mathrm{Na}_{2}$ EDTA resulted in a significant increase in the amount of in vitro dialyzable Fe (7 times more available comparing with the use of ferrous sulfate). Regarding organic acids, Walter, Rjmbach, Most, and Pallauf (1998) performed a study where they supplemented diets containing maize, soybean meal, and corn starch with citric acid $(0,1,2,3$, and $4 \%)$, and found that the addition of this organic acid enhances Mg dialyzability. Engle-Stone, Yeung, Welch, and Glahn (2005) studied Fe bioavailability from an Fephytic acid solution (1:20 Fe/phytic acid molar ratios) to which they added different amounts of ascorbic acid and found an increase in the uptake of Fe in Caco-2 cells. On another study, Beiseigel et al. (2007) evaluated the in vitro and in vivo bioavailability of Fe, adding or not ascorbic acid (AA) from orange juice. The authors found that adding ascorbic acid to the two maize samples significantly enhanced Fe uptake from $2 \%$ to $7 \%$.

Likewise, it has also been demonstrated that the bioaccessibility of $\mathrm{Fe}$ and $\mathrm{Zn}$ is higher when cowpea beans are cooked in a pressure cooker compared with regular pan cooking (Pereira, Carvalho, DellamoraOrtiz, Cardoso, \& Carvalho, 2016).

Regarding the types of beans, white beans showed the highest uptake of $\mathrm{Ca}$ and $\mathrm{Zn}$ in both cooked and canned beans (respectively 23.7 and $32.9 \%$ for $\mathrm{Ca}$, and 26.2 and $58.8 \%$, for $\mathrm{Zn}$ ). Cowpea beans 
presented the highest uptake of $\mathrm{Mg}$ in canned beans (72.5\%) yet not too different from the uptake observed for white beans (71.1\%). In short, it seems that the intestinal uptake of $\mathrm{Ca}, \mathrm{Mg}, \mathrm{Fe}$ and $\mathrm{Zn}$ in white beans is higher in kidney, black or cowpea beans. These results are in good agreement with the literature data. Tako et al. (2009) studied the Fe and $\mathrm{Zn}$ bioavailability to pigs from red and white beans and found that, although not statistically significant, $\mathrm{Fe}$ and $\mathrm{Zn}$ bioavailability was higher in white beans. In vivo assays were conducted also to evaluate this difference. Tako and Glahn (2010) found that chicks (Gallus gallus) fed with red beans for 8 weeks showed a significantly higher expression of divalent metal transporter 1 (DMT1; iron-uptake-transporter), duodenal-cytochrome-B (Dcytb; iron reductase), and ferroportin (iron-exporter) expressions in the intestines of the animals (all indicative of a more Fe deficient state) in comparison with the other conditions (e.g., chicks fed white beans). These in vivo results were of great importance since they supported the in vitro observations, i.e., white beans contain more bioavailable Fe than red beans. This lower Fe bioavailability in red beans (and other colored beans) has been attributed to their higher content of polyphenols. Hu et al. (2006) determined the content of polyphenols in four different types of beans (red, white, black and pinto) and evaluated Fe bioavailability using an in vitro digestion / human Caco-2 cell model. The authors found that white beans contained higher levels of bioavailable Fe compared to red, pinto, and black beans and concluded that these were not due to differences in beans $\mathrm{Fe}$ and phytate content but to the presence of polyphenols, particularly kaempferol. Laparra, Glahn, and Miller (2008) also carried out a similar study and found that kaempferol bioaccessibility can be high in bean seed coats and that this polyphenol can negatively influence Fe uptake. They also found a higher Fe cell uptake for white beans. Other authors have also found a similar inhibitory effect of polyphenols on $\mathrm{Fe}$ bioavailability (Ariza-Nieto, Blair, Welch, \& Glahn, 2007; Beiseigel et al., 2007). However, very recently it has been proved that not all polyphenols have a negative effect on Fe bioavailability and some compounds (e.g., catechin and epicatechin) have shown a promoting effect on Fe cell uptake (Hart, Tako, Kochian, \& Glahn, 2015; Tako, Beebe, Reed, Hart, \& Glahn, 2014). These two last studies also highlighted that kaempferol can in fact be a promoter and not an inhibitor of Fe bioavailability as first described.

\section{Conclusions}

The present work is the first study that presents data on the bioaccessibility and intestinal uptake of several essential minerals (K, $\mathrm{Ca}, \mathrm{Mg}, \mathrm{Fe}, \mathrm{Zn}, \mathrm{Cu}, \mathrm{Mn}$ and $\mathrm{Mo}$ ) in different types of beans prepared by two different cooking procedures. It represents an important contribution to the field of nutrition since it provides information on what type of bean and preparation mode can provide a greater amount of essential minerals in order to meet human dietary requirements of these nutrients.

The results of this study showed that depending on the type of cooking procedure (traditional home cooking or industrial processing, i.e., canned ready-to-eat product) and type of beans (kidney, black, white and cowpea) there is a different bioaccessibility/intestinal uptake of essential minerals. This work emphasizes the need to deepen the knowledge on the bioavailability of minerals in foodstuffs, identifying the factors and food components that most affects it, since it was noticed a remarkable influence of the matrices. This knowledge is very relevant to the improvement of human nutrition concerning essential minerals.

\section{Acknowledgements}

Edgar Pinto and César Oliveira acknowledge Instituto de Ciências e Tecnologias Agrárias e Agro-Alimentares da Universidade do Porto (ICETA) for their contracts NORTE-01-0145-FEDER-0001 and NORTE01-0145-FEDER-000011, respectively. This work received financial support from the European Union (POCI/01/0145/FEDER/007265), from the European Regional Development Fund (ERDF) through COMPETE - Operational Competitiveness Programme and from national funds provided by FCT - Foundation for Science and Technology under the project UID/QUI/50006/2013.

\section{Declarations of interest}

None.

\section{References}

Ariza-Nieto, M., Blair, M. W., Welch, R. M., \& Glahn, R. P. (2007). Screening of iron bioavailability patterns in eight bean (Phaseolus vulgaris L.) genotypes using the Caco-2 cell in vitro model. Journal of Agricultural and Food Chemistry, 55(19), 7950-7956.

Baptista, A., Pinho, O., Pinto, E., Casal, S., Mota, C., \& Ferreira, I. M. P. L. V. O. (2017) Characterization of protein and fat composition of seeds from common beans (Phaseolus vulgaris L.), cowpea (Vigna unguiculata L. Walp) and bambara groundnuts (Vigna subterranea L. Verdc) from Mozambique. Journal of Food Measurement and Characterization, 11(2), 442-450.

BDA (2015). Banca Dati di Composizione degli Alimenti. Accessed from www.bda-ieo.it/. BEDCA (2016). Spanish food composition database. Accessed from http://www.bedca. net/.

Beiseigel, J. M., Hunt, J. R., Glahn, R. P., Welch, R. M., Menkir, A., \& Maziya-Dixon, B. B. (2007). Iron bioavailability from maize and beans: A comparison of human measurements with Caco-2 cell and algorithm predictions. The American Journal of Clinical Nutrition, 86(2), 388-396.

Cámara, F., Barberá, R., Amaro, M. A., \& Farré, R. (2007). Calcium, iron, zinc and copper transport and uptake by Caco-2 cells in school meals: Influence of protein and mineral interactions. Food Chemistry, 100(3), 1085-1092.

CFCD (2016). Czech Centre for Food Composition Database: Czech Food Composition Database, Version 7.16 [online]. Prague: Institute of Agricultural Economics and Information. Accessed from http://www.nutridatabaze.cz/.

Chigwedere, C. M., Olaoye, T. F., Kyomugasho, C., Jamsazzadeh Kermani, Z., Pallares Pallares, A., Van Loey, A. M., ... Hendrickx, M. E. (2018). Mechanistic insight into softening of Canadian wonder common beans (Phaseolus vulgaris) during cooking. Food Research International, 106, 522-531.

CIQUAL (2017). French food composition table. Accessed from https://ciqual.anses.fr/.

CNF (2018). Canadian Nutrient File (CNF). Accessed from https://food-nutrition.canada. ca/cnf-fce/index-eng.jsp.

CoFID (2015). McCance and Widdowson's 'composition of foods. Composition of Foods Integrated Dataset (CoFID). Accessed from https://www.gov.uk/government/ publications/composition-of-foods-integrated-dataset-cofid.

Drago, S. R. (2017). Chapter 5 - Minerals A2 - Galanakis. In M. Charis (Ed.). Nutraceutical and functional food components (pp. 129-157). Academic Press.

Engle-Stone, R., Yeung, A., Welch, R., \& Glahn, R. (2005). Meat and ascorbic acid can promote $\mathrm{Fe}$ availability from $\mathrm{Fe}$ - phytate but not from $\mathrm{Fe}$ - tannic acid complexes. Journal of Agricultural and Food Chemistry, 53(26), 10276-10284.

Etcheverry, P., Grusak, M. A., \& Fleige, L. E. (2012). Application of in vitro bioaccessibility and bioavailability methods for calcium, carotenoids, folate, iron, magnesium, polyphenols, zinc, and vitamins B(6), B(12), D, and E. Frontiers in Physiology, 3, 317

Fernandes, A. C., Nishida, W., \& Da Costa, P. R. P. (2010). Influence of soaking on the nutritional quality of common beans (Phaseolus vulgaris L.) cooked with or without the soaking water: A review. International Journal of Food Science \& Technology, 45(11), 2209-2218.

Fineli (2017). National Food Composition Database in Finland. National Institute for Health and Welfare. Accessed from https://fineli.fi/fineli/en/index.

FSVO (2017). Swiss food composition database. Federal Food Safety and Veterinary Office FSVO. Accessed from http://www.naehrwertdaten.ch/request?xml = MessageData\&xml = MetaData\&xsl $=$ Start\&lan $=$ en\&pageKey $=$ Start.

Gupta, R. K., Gangoliya, S. S., \& Singh, N. K. (2015). Reduction of phytic acid and enhancement of bioavailable micronutrients in food grains. Journal of Food Science and Technology, 52(2), 676-684.

Hambidge, K. M. (2010). Micronutrient bioavailability: Dietary reference intakes and a future perspective. The American Journal of Clinical Nutrition, 91(5), 1430S-1432S.

Hart, J. J., Tako, E., Kochian, L. V., \& Glahn, R. P. (2015). Identification of Black Bean (Phaseolus vulgaris L.) polyphenols that inhibit and promote iron uptake by Caco-2 cells. Journal of Agricultural and Food Chemistry, 63(25), 5950-5956.

Hayat, I., Ahmad, A., Masud, T., Ahmed, A., \& Bashir, S. (2014). Nutritional and health perspectives of beans (Phaseolus vulgaris L.): An overview. Critical Reviews in Food Science and Nutrition, 54(5), 580-592.

Hemalatha, S., Platel, K., \& Srinivasan, K. (2007). Zinc and iron contents and their bioaccessibility in cereals and pulses consumed in India. Food Chemistry, 102(4), 1328-1336.

Hu, Y., Cheng, Z., Heller, L. I., Krasnoff, S. B., Glahn, R. P., \& Welch, R. M. (2006). Kaempferol in Red and Pinto Bean Seed (Phaseolus vulgaris L.) coats inhibits iron bioavailability using an in vitro digestion/human caco-2 cell model. Journal of Agricultural and Food Chemistry, 54(24), 9254-9261.

INSA (2018). Tabela da Composição de Alimentos, V 2.0. Accessed from http://portfir. insa.pt/.

Kloots, W., Op den Kamp, D., \& Abrahamse, L. (2004). In vitro iron availability from iron- 
fortified whole-grain wheat flour. Journal of Agricultural and Food Chemistry, 52(26), 8132-8136.

Laparra, J. M., Glahn, R. P., \& Miller, D. D. (2008). Bioaccessibility of phenols in common beans (Phaseolus vulgaris L.) and iron (Fe) availability to Caco-2 cells. Journal of Agricultural and Food Chemistry, 56(22), 10999-11005.

Liang, J., Han, B.-Z., Nout, M. J. R., \& Hamer, R. J. (2010). In vitro solubility of calcium, iron and zinc in relation to phytic acid levels in rice-based consumer products in China. International Journal of Food Sciences and Nutrition, 61(1), 40-51.

Lioi, L., \& Piergiovanni, A. R. (2013). 2 - European common bean. In M. Singh, H. D. Upadhyaya, \& I. S. Bisht (Eds.). Genetic and genomic resources of grain legume improvement (pp. 11-40). Oxford: Elsevier.

Minekus, M., Alminger, M., Alvito, P., Ballance, S., Bohn, T., Bourlieu, C., ... Brodkorb, A. (2014). A standardised static in vitro digestion method suitable for food - An international consensus. Food and Function, 5(6), 1113-1124.

Nedumaran, S., Abinaya, P., Jyosthnaa, P., Shraavya, B., Parthasarathy, R., \& Bantilan, C. (2015). Grain legumes production, consumption and trade trends in developing countries. Working Paper Series No 60. ICRISAT Research Program, Markets, Institutions and Policies. Patancheru 502 324, Telangana, India: International Crops Research Institute for the Semi-Arid Tropics. $64 \mathrm{pp}$.

NFCT (2017). The Norwegian Food Composition Table. Accessed from http://www. matvaretabellen.no/.

Oliveira, A. P.d., Mateó, B.d. S. O., Fioroto, A. M., Oliveira, P. V.d., \& Naozuka, J. (2018). Effect of cooking on the bioaccessibility of essential elements in different varieties of beans (Phaseolus vulgaris L.). Journal of Food Composition and Analysis, 67, 135-140.

Patterson, C. A., Curran, J., \& Der, T. (2017). Effect of processing on antinutrient compounds in pulses. Cereal Chemistry, 94(1), 2-10.

Pedrosa, M. M., Cuadrado, C., Burbano, C., Muzquiz, M., Cabellos, B., Olmedilla-Alonso, B., \& Asensio-Vegas, C. (2015). Effects of industrial canning on the proximate composition, bioactive compounds contents and nutritional profile of two Spanish common dry beans (Phaseolus vulgaris L.). Food Chemistry, 166, 68-75.

Pereira, E. J., Carvalho, L. M. J., Dellamora-Ortiz, G. M., Cardoso, F. S. N., \& Carvalho, J. L. V. (2016). Effect of different home-cooking methods on the bioaccessibility of zinc and iron in conventionally bred cowpea (Vigna unguiculata L. Walp) consumed in Brazil. Food \& Nutrition Research, 60. https://doi.org/10.3402/fnr.v3460.29082.

Rebello, C. J., Greenway, F. L., \& Finley, J. W. (2014). Whole grains and pulses: A comparison of the nutritional and health benefits. Journal of Agricultural and Food Chemistry, 62(29), 7029-7049.

Suliburska, J., \& Krejpcio, Z. (2014). Evaluation of the content and bioaccessibility of iron, zinc, calcium and magnesium from groats, rice, leguminous grains and nuts. Journal of Food Science and Technology, 51(3), 589-594.

Tako, E., Beebe, S. E., Reed, S., Hart, J. J., \& Glahn, R. P. (2014). Polyphenolic compound appear to limit the nutritional benefit of biofortified higher iron black bean (Phaseolus vulgarisL.). Nutrition Journal, 13(1), 28.

Tako, E., \& Glahn, R. P. (2010). White beans provide more bioavailable iron than red beans: Studies in poultry (Gallus gallus) and an in vitro digestion/Caco-2 model. International Journal for Vitamin and Nutrition Research, 80(6), 416-429.

Tako, E., Glahn, R. P., Laparra, J. M., Welch, R. M., Lei, X., Kelly, J. D., ... Miller, D. D. (2009). Iron and zinc bioavailabilities to pigs from red and white beans (Phaseolus vulgaris L.) are similar. Journal of Agricultural and Food Chemistry, 57(8), 3134-3140.

USDA (2018). USDA Food Composition Databases. United States Department of Agriculture Agricultural Research Service Accessed from https://ndb.nal.usda.gov/ $\mathrm{ndb} /$.

van Kuppeveld, F. J., van der Logt, J. T., Angulo, A. F., van Zoest, M. J., Quint, W. G., Niesters, H. G., ... Melchers, W. J. (1992). Genus- and species-specific identification of mycoplasmas by $16 \mathrm{~S}$ rRNA amplification. Applied and Environmental Microbiology, 58(8), 2606-2615.

Viadel, B., Barberá, R., \& Farré, R. (2006). Effect of cooking and legume species upon calcium, iron and zinc uptake by Caco-2 cells. Journal of Trace Elements in Medicine and Biology, 20(2), 115-120.

Vitali, D., Vedrina Dragojević, I., \& Šebečić, B. (2008). Bioaccessibility of Ca, Mg, Mn and $\mathrm{Cu}$ from whole grain tea-biscuits: Impact of proteins, phytic acid and polyphenols. Food Chemistry, 110(1), 62-68.

Walter, T., Pizarro, F., \& Olivares, M. (2003). Iron bioavailability in corn-masa tortillas is improved by the addition of disodium EDTA. The Journal of Nutrition, 133(10), 3158-3161.

Walter, A., Rjmbach, G., Most, E., \& Pallauf, J. (1998). Effect of citric acid supplements to a maize-soya diet on the in vitro availability of minerals, trace elements, and heavy metals. Journal of Veterinary Medicine Series A, 45(1-10), 517-524. 